\title{
AC 2012-3077: ONE OR MANY? ASSESSING DIFFERENT DELIVERY TIMING FOR INFORMATION RESOURCES RELEVANT TO ASSIGN- MENTS DURING THE SEMESTER. A WORK-IN-PROGRESS
}

\section{Prof. Amy S. Van Epps, Purdue University, West Lafayette}

\begin{abstract}
Amy Van Epps, M.S.L.S., M.Eng., is an Associate Professor of library science and Engineering Librarian and Coordinator of Instruction at the Siegesmund Engineering Library, Purdue University. Her research interests include information literacy, effective teaching, and integration methods for information literacy into the curriculum and ethical writing skills of engineering students.
\end{abstract}

\section{Ms. Megan R. Sapp Nelson, Purdue University, West Lafayette}

Megan Sapp Nelson is Associate Professor of library sciences at Purdue University Siegesmund Engineering Library. She is liaison to the schools of Civil and Electrical Engineering and Earth and Atmospheric Sciences, and related College of Technology disciplines. You can contact her at msn@purdue.edu. 


\section{One or Many? Assessing different delivery timing for information resources relevant to assignments during the semester. A work-in-progress.}

\section{Introduction}

Three sections of COM 114, an introductory communications course targeted to freshman engineers were given information literacy instruction in class. Two sections were given information in four 12 minute, integrated information literacy (otherwise known as "just in time") instruction sessions, prior to the assignment that the instruction was intended to support. One section was given a traditional "one-shot" instruction session of one hour during the second week of the semester. The authors used the coding method devised by Wertz et al. ${ }^{1}$ to evaluate the quality of citations included in the bibliographies for each assignment.

\section{Review of Literature}

There is no single and most effective approach to providing library instruction and the use of a variety of instructional methods, reaching ever-widening audiences, and addressing everchanging needs, is preferred ${ }^{2,3}$. $\operatorname{Stec}^{4}$ noted that the instructional method must become more in depth and extensive in relation to the number of information literacy objectives that need to be taught. It is unreasonable for skills gained by professors and librarians over years to be transferred in one hour of class ${ }^{5,6}$. Martin ${ }^{7}$ discovered that there is not a statistical relationship between the quality of sources used by students and one-shot instruction. However, multiple library instruction sessions or for-credit information literacy courses may improve use of credible sources in assignments ${ }^{7}$.

In recent years, the effectiveness of "one-shot" or single session library instruction sessions has been questioned, leading to the evaluation of the effectiveness of one-shot sessions ${ }^{8-10}$. Librarians indicated that, in their opinion, the move away from one-shot sessions was a positive development in information literacy instruction ${ }^{2}$. Hollister and Coe found that librarians did not consider one-shot instruction sessions obsolete, so much as an appropriate "method of instruction \{...if $\}$ aimed to assist specific classes with specific research assignments"2. One-shot sessions are considered to be effective tools for orientation to the library ${ }^{7}$.

The transformation of one-shot sessions is accomplished through either the integration of active (or problem based) learning activities or providing point of need instruction for specific assignments ${ }^{6,11}$. Using problem-based learning in a one-shot session creates a more effective learning experience in the absence of course integration and collaboration with the course instructor $^{12}$.

Curricular integration of information literacy has been found to be highly effective for the transfer of skills ${ }^{5,12,13}$. However, it is frequently difficult for librarians to create inroads into existing courses ${ }^{2}$. Those who do integrate into existing courses need to develop relationships 
with professors and prepare assignments, presentations, and curriculum in conjunction with the professor or class syllabus ${ }^{5,11,13-15}$. Determining the appropriate point in the semester to present content is tricky ${ }^{3}$. Spreading information literacy content over multiple shorter sessions that is normally packaged into a one-shot session allows students to have more in depth exposure to both information literacy skills and relevant content for assignments, which in turn increases the likelihood that students will retain information literacy skills ${ }^{11,14,16}$. Students are more likely to recognize librarians through repeated exposure in class ${ }^{11,14}$.

Communication classes have been provided with educational interventions by librarians ${ }^{14}$. Embedded librarianship was shown to be very successful in a first year oral communication class, when the content is integrated into the curriculum of the course ${ }^{14}$. The presence of a librarian in a freshman communication course fully integrated in the teaching team led to improvements in quality of sources in bibliographies ${ }^{15}$.

The accreditation standards for engineering programs require that proficiency in written and oral communication and lifelong learning be demonstrated by all graduates ${ }^{17,18}$. Generally, communications skills are relatively straightforward to assess, while assessment of lifelong learning (including information literacy) presents challenges ${ }^{1,19}$. In the process of developing assessments for lifelong learning and information literacy, observations were made regarding the performance of freshman engineers ${ }^{1,20}$. First year engineers were shown to cite web sites more and books less frequently than more advanced undergraduate engineering students ${ }^{21}$. Yu et al concluded "With first-year students, we need to concentrate on the basics and build on this progressively in later years. For example, with the first-year students we should emphasise $\{$ sic $\}$ finding, interpreting, and citing books, journal articles, and Web sites."21. Underclassman engineers were specifically studied with regards to their response to a traditional lecture based information literacy instruction. Freshman and sophomore engineers retained less information in a lecture based format, compared with problem based learning ${ }^{22}$.

\section{Research Question:}

Is there a noticeable difference in the quality of citations in student assignments when "just-intime" instruction is used as opposed to a "one-shot" session?

The researchers' assumption is that the sections which received the just-in-time instruction at the point when each assignment was given would have better citations, both in quantity and quality than the section which received the one-shot session at the start of the semester.

\section{Methodology}

\section{Setting/ Courses}

The class studied is a first year communications class that focuses on oral communication skills for students in all disciplines. Several sections of the class are associated with Learning 
Communities $^{23,24}$, and as a result have only engineering students enrolled. Two different course instructors contacted engineering librarians asking them to present library resources to the students that will help with the four speech assignments to be completed through the semester. For one instructor/librarian team a single "one-shot" instruction session was given during the second week of the semester. For the other instructor/librarian team, which worked with 2 sections of the class, the same content was delivered in 4 mini-lectures, each given shortly after the assignment was given to the students. The same materials and supporting LibGuide were used by both instructors for the sessions offered. The library instruction focused on the best resources for the types of speeches the students would be giving. Proper citation format was mentioned only in passing and a link to the Online Writing Lab (OWL) at Purdue University was included in the LibGuide.

\section{Description of Assignments}

During the semester, all of the students completed four speech assignments, some individually and some as part of groups. As a requirement of the assignment, an outline and references for each speech were completed and submitted. The first two speeches the students gave were informative, the first on an engineering innovation, and the second on how a machine or process works with particular attention paid to the intended audience level (e.g. middle school students, general public, engineers). The third speech was persuasive and asked the presenter to persuade classmates to donate to a particular charity and the fourth speech was a group presentation. More complete descriptions of the four speeches can be found as an appendix.

\section{Sample}

The students in the sections librarians were asked to teach comprised the convenience set. The full data set for 4 assignments in 3 sections provided a total sample size of 234 assignments. Since there were two sections of the class that received the just-in-time (JIT)/embedded teaching model, and only one that received the one-shot instruction, the sample was balanced to avoid skewing the results toward the submissions of the students in the JIT sections. The initial comparison of citations was completed on a small sample of one paper from each assignment for each team, for a total of 8 papers. The items examined by this first analysis were randomly selected from the submissions for all sections.

\section{Data Analysis procedure}

The data was drawn from the student outlines and bibliographies that were turned in, and then passed along to the librarians by the section instructors once any information that could identify a particular student was removed. Citations were coded both for type of information resource used and quality of the resource based on its scholarly content and lack of bias, and the completeness of the reference included.

The results for quality of resources used and the relevance for the particular assignment were compared across the sections for each instructional team. 
While it was impossible to control for the instructor/librarian teaching style variations and differences inherent from having different students in each class, the content presented by the librarians was aligned and a LibGuide was used to ensure the students shared a resource to return to for guidance as the semester progressed. In this way as many variables as possible to control easily, were controlled.

\section{Inter-rater Reliability}

The consensus estimate of Inter-rater Reliability (IRR) was calculated as a simple percentagreement figure. The agreement percentage is calculated by taking the number of items that are coded identically between judges and divided by the total number of items rated ${ }^{25}$. To minimize the time spent analyzing data, each of the librarians coded assignments on their own. A small sample of 8 items was taken from the original 234 items, representing one of each assignment for each instructional method used. Both raters coded all 8 items based on the coding framework developed by Wertz et $\mathrm{al}^{1}$. Each citation is rated for type of material, quality of resource based on both audience and treatment (bias), and completeness of the citation creating 4 ratings for each citation. After the initial 8 items were rated, the two librarians met and checked how well their use of the framework matched. Differences were discussed until a common understanding of the coding framework was established. The consensus estimate of inter-rater reliability was calculated as $85.1 \%$.

The largest source of variation between raters came in determining complete, incomplete and improper citations, which accounts for $44 \%$ of the differences in codes applied. More clarity on improper and complete reference and what constitutes "easily traceable" could bring the IRR up to $91.6 \%$.

\section{Data analysis}

Prior to initial ratings for testing inter-rater reliability the researchers met to look over the coding framework to ensure agreement on the sections to be used and how they would be applied.

- The authors used the first three sections of the coding framework presented in the Wertz et al ${ }^{1}$ article

○ The later sections are designed to determine the appropriateness of the reference for the particular point being made in the student work. This information was not available because the librarians were not present to witness the formal presentation of the speech.

- The authors agreed that for EDU sites, more than the domain address would be used to determine type of resource, thus checking for official EDU pages as opposed to individual pages supported by the school.

- Section 3 of the Wertz et al $^{1}$ framework needed to be modified to accommodate the type of assignment (speeches). 
- In-text citations were not analyzed as the speeches themselves were not witnessed by the librarians and inclusion of the information was inconsistent across the outlines.

- Coding of references at the end of the outline followed the framework for indication of complete/incomplete, improper, or missing citations.

A random selection of assignments was gathered for the initial application of the coding framework. One outline with references for each assignment was selected per course instructor.

The authors observed that it was necessary to do the citation coding with a web browser open, as it was not possible to tell the intent of the cited pages (informational, biased, entertainment) without looking at the page itself.

\section{Coding framework modifications}

During discussion between the two raters to verify agreement on ratings and use of codes, several modifications were proposed to the coding framework. Some required modifications were the results of applying the framework to non-engineering specific assignments and some were the expected refinements and adjustments resulting from use of the framework developed by researchers exploring different objectives than the coding schema authors.

In the monographs category of section 1 , a couple of codes were identified as missing. The two codes added to this section were BOOK, for a typical book that is not a textbook, and DICT, dictionary, which is required to code one instance in the test set. Since encyclopedia is included in the codes, it was logical to also include dictionary, as a resources used in a similar fashion to encyclopedias and as a common tool for speeches.

Some clarification between the use of newspaper and e-news sources as codes, one in the periodicals classification and the other in the web resources classification, appeared to be distinguishing between print and electronic formats and was applied differently in this project. The authors coded any newspaper publication as NWSP in the periodicals classification, regardless of format, which opened a discussion of what would be included in the e-news category. The e-news designation used for this project includes those sources which are just electronic and non-print, including television, radio and web. Examples of what qualify as enews sources are CNN and NPR, but would not include the web version of the New York Times or the Wall Street Journal.

Codes for statistical or factual information and product sheets seemed to be missing during initial use of the framework. STAT was subsequently identified in the monograph classification of section1, but seemed a poor fit. As a result, a new classification of Facts and Figures was created for future use and includes the codes STAT, for statistical information and data sets, and PROD, for product information and data sheets, either third party, such as Alloy Digest pages or direct from the manufacturer. In addition, the materials included in the facts and figures classification 
does not easily fit within scholarly or popular information, thus it would be classified as technical literature in the audience identification section.

Finally, the differentiation between incomplete and improper references caused some issues with determining inter-rater reliability. One issue was the amount of work required for a reference to be traceable. Despite some of the test set being ultimately traceable by a librarian, the amount of work required in those cases was extreme. As such, an improper (IMP) reference is largely complete and recognizable, while an incomplete (INC) reference cannot be found without additional database searching to identify the citation elements and subsequently locate the source. Further refinement of the differences between Incomplete and Improper will also help raise the IRR. The language in the Wertz et al $^{1}$ coding framework can be interpreted in different ways.

A revised version of the coding framework, as used for this project, is included as an appendix.

\section{Findings}

\section{References analysis}

The test set of 8 assignments provided 43 references to be analyzed regarding student use of resources and ability to document those sources. These numbers gave an average of 5.3 references per outline $(43 / 8=5.3)$, which may seem high for first year students in a speech class. The high average can partially be explained by one assignment which contained 16 references, thus skewing the average for this set. If the outlier is removed and the average retaken $(27 / 7=3.85)$, the average is 3.85 references per outline. While this is still a bit higher than expected, based on an average of 3.57 references in first-year student papers found by KnightDavis and Sung ${ }^{26}$, it is a reasonable number given the assignments all asked for a minimum of 3 citations.

\section{Resource Quality}

Using the quality quadrants presented by Wertz et $\mathrm{al}^{1}$, the 43 references were rated for quality. Of the full set of 43, 4 were removed from the quality assessment because they were coded as general web (GWEB) resources, and with a broken link it was impossible to determine audience or intent of the resource. The remaining 39 references were analyzed, with $28.2 \%$ of the set classified as high quality (scholarly and informative), $66.7 \%$ as medium quality (popular and informative) and only $5.1 \%$ as low quality (popular and bias or entertainment).

The authors are not surprised by this result. The nature of the speech communication course is well suited to the use of popular and more accessible resources and does not require the research or scholarly publications that design assignments or research papers would use. It is good to see $94.9 \%$ of the resources used were classified as informative. Just a small percentage of the 
resources would be classified as containing bias, even for those assignments when students were speaking about charity organizations.

\section{Cross-section analysis}

For the cross-section analysis, the quality determination was divided by which form of library instruction the students received; one-shot or 4 mini-lectures. The one-shot assignments included 14 references and the mini-lecture assignments included 29 references. The first point that jumped out is the 4 references which needed to be eliminated due to inability to follow the link and determine quality all appeared in the one-shot instruction model. Alternately, both of the low quality resources used appeared in the mini-lecture section.

The one-shot section presented the following break-down of references by quality. $28.6 \%$ were unable to be classified due to broken links, $35.7 \%$ high quality and $35.7 \%$ medium quality.

The mini-lectures section presented a different pattern, with $20.7 \%$ high quality, $72.4 \%$ medium quality and $6.9 \%$ low quality. By removing the outlier from this data set, the pattern of resource quality used changes to be $23.1 \%$ high quality, $61.5 \%$ medium quality, and $14.3 \%$ low quality, still heavily skewed to the medium quality resources.

\section{Discussion}

The data in this instance does not show a pattern of higher quality resources being used by those students who interacted with the librarian before each assignment instead of those who had a single session at the beginning of the semester. Given that the analysis in this paper is based on the test set of data, the sample size is too small to run any statistical analysis between the sections to determine if the differences are significant. In addition, the outlier of the group assignment with 16 references may also be skewing the percentages for quality used within each group.

Discussion of the citations themselves and any feedback on the quality or completeness was provided by the course instructors, not the librarians. Therefore, the authors have no sense of how much of that feedback students received. Analysis of the number of complete citations per assignment shows consistent patterns across sections of $60-75 \%$ complete on the first couple of assignments, with a slight increase on the second assignment, a significant drop off for the third assignment in the $20-25 \%$ range complete citations for both instructors, and then a jump to between 80 and 100\% complete citations by the final assignment. The third assignment, which focused on information about charities, used different types of resources from the other three assignments. Citation completeness for assignment 3 appears to indicate that students were outside of their comfort area for material types and how to write complete citations for those items. 
A more complete analysis using a broader sample from the original set of assignments is planned and will be reported in a subsequent publication.

\section{Conclusions and Future Directions}

Given that this work is presenting the findings of preliminary data analysis, it is difficult to draw solid conclusions from this data. Further analysis of a larger set of assignments may present patterns that indicate the effectiveness of one style of intervention over the other.

Future research potentially includes conducting a similar study in a class where the information being gathered by the students and included in the assignments is more technical in nature.

\section{References}

1. Wertz, R.E.H., Ross, M.C., Fosmire, M., Cardella, M.E. \& Purzer, S. Do Students Gather Information to Inform Design Decisions? Assessment with an Authentic Design Task in First-Year Engineering. Annual Conference and Exposition of the American Society for Engineering Education AC 2011-2776 (2011).

2. Hollister, C.V. \& Coe, J. Current trends vs. traditional models: librarians' views on the methods of library instruction. College and Undergraduate Libraries 10, 49-63 (2003).

3. Tumbleson, B.E. \& Burke, J.J. Embedded Librarianship is Job One: Building on Instructional Synergies. Public Services Quarterly 6, 225-236 (2010).

4. Stec, E. Using best practices: librarians, graduate students and instruction - ProQuest. Reference Services Review 34, 97-116 (2006).

5. Jacobs, H.L.M. \& Jacobs, D. Transforming the One-Shot Library Session into Pedagogical Collaboration: Information Literacy and the English Composition Class. Reference \& User Services Quarterly 49, $72-82$ (2009).

6. Badke, W. Ramping up the One-Shot. Online 33, 47-49 (2009).

7. Martin, J. The Information Seeking Behavior of Undergraduate Education Majors: Does Library Instruction Play a Role? Evidence Based Library and Information Practice 3, $4-17$ (2008).

8. Riggs, D.E. What's in Store for Academic Libraries? Leadership and Management Issues. Journal of Academic Librarianship 23, 3-8 (1997).

9. Byerly, G., Downey, A. \& Ramin, L. Footholds and foundations: setting freshmen on the path to lifelong learning. Reference Services Review 34, 589-598 (2006).

10. Fain, M. Assessing Information Literacy Skills Development in First Year Students: A Multi-Year Study. Journal of Academic Librarianship 37, 109-19 (2011).

11. Bean, T.M. \& Thomas, S.N. Being like Both: Library Instruction Methods That Outshine the One-Shot. Public Services Quarterly 6, 237-249 (2010). 
12. Kenney, B.F. Revitalizing the one-shot instruction session using problem-based learning. Reference \& User Services Quarterly 47, 386-391 (2008).

13. Brendle-Moczuk, D. Encouraging students' lifelong learning through graded information literacy assignments. Reference Services Review 34, 498-508 (2006).

14. Weaver, K.D. \& Pier, P.M. Embedded Information Literacy in the Basic Oral Communication Course: From Conception Through Assessment. Public Services Quarterly 6, 259-270 (2010).

15. Hall, R.A. The "embedded" librarian in a freshman speech class: information literacy instruction in action. College \& Research Libraries News 69, 28-30 (2008).

16. Gandhi, S. Faculty-Librarian Collaboration to Assess the Effectiveness of a Five-Session Library Instruction Model. Community \& Junior College Libraries 12, 15-48 (2005).

17. Criteria for accrediting engineering programs: Effective for evaluations during the 2011-2012 accreditation cycle. (ABET, Inc.: Baltimore, MD, 2010).

18. Volkwein, J.F., Lattuca, L.R., Terenzini, P.T., Strauss, L.C. \& Sukhbaatar, J. Engineering change: a study of the impact of EC2000. International Journal of Engineering Education 20, 318-328 (2004).

19. Shuman, L.J., Besterfield-Sacre, M. \& McGourty, J. The ABET “professional skills" - Can they be taught? Can they be assessed? 94, 41-55 (2005).

20. Ross, M.C., Fosmire, M., Wertz, R.E.H., Cardella, M.E. \& Purzer, S. Lifelong learning and information literacy skills and the first year engineering undergraduate: Report of a self-assessment. 118th ASEE Annual Conference and Exposition, June 26, 2011 - June 29, 2011 (2011).

21. Yu, F., Sullivan, J. \& Woodall, L. What can students' bibliographies tell us? Evidence based information skills teaching for engineering students. Evidence Based Library and Information Practice 1, 12-22 (2006).

22. Hsieh, C. \& Knight, L. Problem-based learning for engineering students: an evidence-based comparative study. The Journal of Academic Librarianship 34, 25-30 (2008).

23. Student Access Transition \& Success. College of Engineering Learning Communities. (2011). <http://www.purdue.edu/sats/learning_communities/profiles/engineering/index.html>

24. Student Access Transition \& Success. Learning Communities. (2011). <http://www.purdue.edu/sats/learning_communities/index.html>

25. Stemler, S.E. A Comparison of Concensus, Consistency, and Measurement Approaches to Estimating Interrater Reliability. Practical Assessment, Research and Evaluation 9, (2004).

26. Knight-Davis, S. \& Sung, J.S. Analysis of Citations in Undergraduate Papers 1. College \& Research Libraries 69, 447-458 (2008). 


\section{Appendix - Coding Framework for Speech Outlines}

\begin{tabular}{|c|c|c|c|c|}
\hline \multicolumn{2}{|c|}{$\begin{array}{c}\text { Sub- } \\
\text { Classification } \\
\end{array}$} & Code & Definition & Description/Example \\
\hline \multirow{29}{*}{ 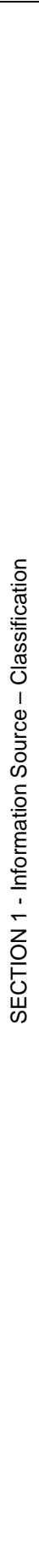 } & Monographs & BOOK & Books & Provides in-depth details of specific topic or related group of topics. \\
\hline & & HNBK & $\begin{array}{l}\text { Handbooks, Guides, } \\
\text { and Manuals }\end{array}$ & Provides quick facts, formulas, equations and/or procedures \\
\hline & & STND & Standards & Provides standards and/or codes \\
\hline & & TXBK & Textbooks & $\begin{array}{l}\text { Provides in-depth details of specific topic or related group of topics. } \\
\text { Includes problem sets, intended for class use. }\end{array}$ \\
\hline & & ENCL & Encyclopedias & Provides overview of a wide range of topics \\
\hline & & DICT & Dictionaries & Provides definitions and word origins \\
\hline & & TECH & Technical Reports & Official reports published by government or public agencies \\
\hline & & PATN & Patents & Existing and/or pending U.S. or foreign patents. \\
\hline & Periodicals & NWSP & Newspapers & New York Times, Wall Street Journal, Journal Gazette \\
\hline & & PMAG & Popular Magazines & Good Housekeeping, People, Parents \\
\hline & & TMAG & Trade Magazines & Engineering News Record, Contracting Business \\
\hline & & NMAG & News Magazines & Newsweek, Time \\
\hline & & & Journal Articles & $\begin{array}{l}\text { Journal of Solar Energy Engineering, Journal of Energy Resources } \\
\text { Technology }\end{array}$ \\
\hline & $\begin{array}{c}\text { Web } \\
\text { Resources }\end{array}$ & COM & Commercial & $\begin{array}{l}\text { Website published by commercial enterprises (i.e. ".com") } \\
\text { www.ge.com, www.lightingexpert.com }\end{array}$ \\
\hline & & ENWS & News Organizations & $\begin{array}{l}\text { Websites or broadcasts by non-print based news organizations } \\
\text { www.cnn.com, www.bbc.com, www.npr.org }\end{array}$ \\
\hline & & GOV & Government Agencies & $\begin{array}{l}\text { Websites or reports published by federal, state, local, or foreign } \\
\text { government entities }\end{array}$ \\
\hline & & ORG & $\begin{array}{l}\text { Non-Profit } \\
\text { Organizations }\end{array}$ & $\begin{array}{l}\text { Websites published by non-profit organizations } \\
\text { www.greenpeace.org }\end{array}$ \\
\hline & & EDU & $\begin{array}{l}\text { Scholarly } \\
\text { Organizations }\end{array}$ & $\begin{array}{l}\text { Websites published by educational entities } \\
\text { www.[university_name].edu }\end{array}$ \\
\hline & & PERS & Personal & $\begin{array}{l}\text { Websites authored by amateurs and non-experts (i.e. blogs, personal } \\
\text { webpages, etc.) Includes personal space on ".edu" sites }\end{array}$ \\
\hline & & DMED & Digital Media & Digital images or videos \\
\hline & Internal & PEER & Peers & Correspondence with peers \\
\hline & & EXPT & Experts & Correspondence with experts \\
\hline & & INVT & Stakeholders & Formal interviews with stakeholders \\
\hline & & SURV & Surveys & Formal or informal surveys developed by students \\
\hline & & OBSV & Observations & Measured observations recorded by students \\
\hline & & IMAG & Images & Photos and/or videos taken by students \\
\hline & Unknown & GWEB & Generic Website & $\begin{array}{l}\text { Citation that is clearly a Web Resource, but cannot be coded } \\
\text { (e.g. broken URL) }\end{array}$ \\
\hline & & UNKN & Unknown & Citation is incomplete and cannot be classified \\
\hline & $\begin{array}{l}\text { Facts \& } \\
\text { Figures }\end{array}$ & $\begin{array}{l}\text { STAT } \\
\text { PROD }\end{array}$ & $\begin{array}{c}\text { Statistical Compilations } \\
\text { Product Information }\end{array}$ & $\begin{array}{l}\text { Published data sets } \\
\text { Third party or manufacturer data on produce specifications. }\end{array}$ \\
\hline
\end{tabular}


Classification Code

Definition

Description/Example

\begin{tabular}{|c|c|c|c|c|}
\hline & Classification & Code & Definition & Description/Example \\
\hline \multirow{2}{*}{ 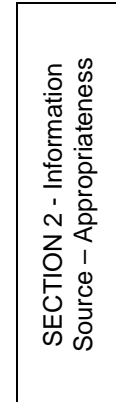 } & Audience & $\begin{array}{c}\mathrm{SCH} \\
\mathrm{TECH} \\
\text { POP }\end{array}$ & $\begin{array}{c}\text { Scholarly } \\
\text { Technical Data } \\
\text { Popular }\end{array}$ & $\begin{array}{l}\text { Journal articles, conference papers, textbooks, technical reports, etc. } \\
\text { Data, product datasheets, product specifications, trade publications } \\
\text { Non-scientific / non-technical }\end{array}$ \\
\hline & Purpose & $\begin{array}{l}\text { INF } \\
\text { BIAS } \\
\text { ENT }\end{array}$ & $\begin{array}{l}\text { Informative } \\
\text { Biased/ } \\
\text { Persuasion } \\
\text { Entertainment }\end{array}$ & $\begin{array}{l}\text { Information is provided with minimal bias (i.e. gives information to } \\
\text { make informed decisions) } \\
\text { Information is advocating a particular idea or group of ideas from a } \\
\text { biased perspective (i.e. give assertions of what is best) } \\
\text { Information is meant for entertainment, not educational use }\end{array}$ \\
\hline 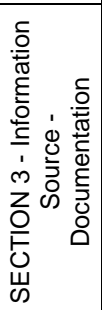 & References & $\begin{array}{l}\text { RCOM } \\
\text { RIMP } \\
\text { RIMC } \\
\text { RMIS }\end{array}$ & $\begin{array}{l}\text { Incomplete } \\
\text { Missing }\end{array}$ & $\begin{array}{l}\text { Citation is given in a clear format with all necessary elements, such } \\
\text { that the original source is easily traceable } \\
\text { Citation has one or more elements wrong (i.e. incorrect URL, etc.) but } \\
\text { the original source is ultimately traceable } \\
\text { Information is cited, but missing crucial elements (i.e. title, publisher, } \\
\text { URL, etc.) such that the original source is not traceable } \\
\text { No reference is given }\end{array}$ \\
\hline
\end{tabular}

0
$\mathbb{0}$
0
$\mathbb{D}$
$N$
$N$
0
0
0
$\vec{N}$ 


\section{Appendix - Description of Speech Assignments}

\section{Network Learning Community \\ COM 114 Speech Assignments}

\section{Speech \#1: Informative \\ Length: 3-4 Minutes}

Description: In this speech, you will present to the class about one of the top Engineering innovations of the $20^{\text {th }}$ century. You will be given a list of topics from your instructor. You will explain to the class what the innovation was and what impact this innovation has had on the way that people live, work, or how we understand the world. This assignment will require a small amount of research, and each presentation must include two sources. This assignment emphasizes organization and delivery. It is important that you present the material in an appropriate organizational pattern for an oral presentation. You must have an introduction, body, and conclusion. This will help your audience understand and retain the information you provide. You also will be asked to pay specific attention to your delivery.

\section{Speech \#2: Informative}

\section{Length: 4-5 Minutes}

Description: In this speech we will be focusing on how to report information to different audiences with differing levels of knowledge. For this assignment the class will be divided into groups of three. Each small group will be assigned a machine, process, or technological innovation works. Each individual in the group will also be assigned a target audience; fellow engineers, potential consumers, or high school juniors. Although the groups of three will have the same topic and will present on the same day, you do not need to collaborate on your presentations. Your task will be to explain how this machine, process, or technology works in a way that is appropriate for your target audience. This presentation must be based on at least 3 sources and use an appropriate organizational pattern and include a clear intro, body, and conclusion.

\section{Speech \#3: Persuasive}

\section{Length: 5-6 Minutes}

Description: For this presentation you are going to persuade your classmates to support a charity or nonprofit organization by donation their time, money, or tangible goods. You are going to persuade your audience to volunteer or to donate money or other tangible goods. You will use a problem-solution format. First explain what the problem is and then explain why your audience should support the organization you chose to help that problem. For example, you might want to persuade your audience to donate blood. You would first talk about the problem which is the need for blood and possible blood shortages and then explain how being a blood donor can help 
solve that problem. You can also talk about the personal benefits one might get from supporting the cause you chose. These can be national or local organizations.

\section{Speech \#4: Group Presentation}

Length: 30-35 Minutes

Notes: 1 typed sheet OR $14 x 6$ notecard per person

Description: In this speech, you must take various concepts/products (a car, a computer, a home, a classroom, a restaurant, etc.) and completely RETHINK the object or space to make it more user-friendly and/or efficient. You must develop visuals of your new product so the audience can visualize it. Your audience for this speech is a venture capital firm, so be sure to "pitch" your product as well as you can. 